\title{
The Effects of Tocotrienol on Bone Peptides in a Rat Model of Osteoporosis Induced by Metabolic Syndrome: The Possible Communication between Bone Cells
}

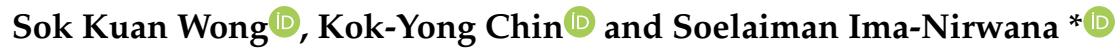 \\ Department of Pharmacology, Faculty of Medicine, Universiti Kebangsaan Malaysia, Jalan Yaacob Latif, \\ Bandar Tun Razak, Cheras 56000, Kuala Lumpur, Malaysia \\ * Correspondence: imasoel@ppukm.ukm.edu.my; Tel.: +603-91459579
}

Received: 15 August 2019; Accepted: 2 September 2019; Published: 9 September 2019

\begin{abstract}
A positive association between metabolic syndrome (MetS) and osteoporosis has been demonstrated in previous animal studies. The mechanisms of MetS in orchestrating the bone remodelling process have traditionally focused on the interactions between mature osteoblasts and osteoclasts, while the role of osteocytes is unexplored. Our earlier studies demonstrated the bone-promoting effects of tocotrienol using a rat model of osteoporosis induced by MetS. This study aimed to investigate the expression of osteocyte-derived peptides in the bone of rats with MetS-induced osteoporosis treated with tocotrienol. Age-matched male Wistar rats (12-week-old; $n=42)$ were divided into seven experimental groups. Two groups served as the baseline and normal group, respectively. The other five groups were fed with a high-carbohydrate high-fat (HCHF) diet to induce MetS. The five groups of HCHF animals were treated with tocopherol-stripped corn oil (vehicle), annatto tocotrienol (60 and $100 \mathrm{mg} / \mathrm{kg}$ ), and palm tocotrienol (60 and $100 \mathrm{mg} / \mathrm{kg}$ ) starting from week 8. At the end of the study, the rats were sacrificed and their right tibias were harvested. Protein was extracted from the metaphyseal region of the proximal right tibia and levels of bone peptides, including osteoprotegerin (OPG), soluble receptor activator of nuclear factor-kappa B ligand (sRANKL), sclerostin (SOST), Dickkopf-related protein 1 (DKK-1), fibroblast growth factor-23 (FGF-23), and parathyroid hormone (PTH), were measured. The vehicle-treated animals displayed higher levels of sRANKL, SOST, DKK-1, FGF-23, and PTH as compared to the normal animals. Oral supplementation of annatto and palm tocotrienol $(60$ and $100 \mathrm{mg} / \mathrm{kg})$ reduced the levels of sRANKL and FGF-23 in the HCHF animals. Only $100 \mathrm{mg} / \mathrm{kg}$ annatto and palm tocotrienol lowered SOST and DKK-1 levels in the HCHF animals. In conclusion, tocotrienol exerts potential skeletal-promoting benefit by modulating the levels of osteocytes-derived bone-related peptides.
\end{abstract}

Keywords: osteoblast; osteoclast; osteocyte; osteoporosis; vitamin E

\section{Introduction}

The occurrence of three out of five medical abnormalities (obesity, hyperglycaemia, hypertension, hypertriglyceridemia and low high-density lipoprotein (HDL) cholesterol), also termed as metabolic syndrome (MetS), might predispose an individual to skeletal disturbance [1]. Our earlier studies demonstrated that the rats fed with high-carbohydrate high-fat (HCHF) diet fully developed MetS after 12 weeks, characterized by the fulfilment of all criteria of MetS (increased abdominal circumference, blood glucose, blood pressure, triglycerides, and lowered HDL cholesterol) [2]. Significant bone loss was also detected subsequent to the establishment of MetS, with the alteration of bone histomorphometric parameters being characterized by increased osteoclastic activity and reduced osteoblastic activities. 
The imbalance between bone formation and resorption processes favoured deterioration of bone microstructure and bone strength $[3,4]$. The maintenance of bone integrity relies on the balance between the tightly-coupled bone formation and resorption, being mainly governed by osteoblasts and osteoclasts. The role of osteocytes in MetS-mediated changes in bone metabolism receives far less attention when compared to osteoblasts and osteoclasts.

Osteocytes are the most abundant bone cells that are differentiated from osteoblasts and permanently residing within the mineralized bone matrix. They act as mechanosensors, communicators and coordinators in maintaining bone quality. Osteocytes detect mechanical and hormonal stimuli as well as transmitting the osteocyte-secreted molecules through the lacunar-canalicular network, allowing for communication with other bone cells to regulate bone resorption and formation [5]. Osteocytes produce most of the molecular mediators that are produced by osteoblasts, with osteocytes being the more dominant source than osteoblasts [6]. Osteocytes play a critical role in the regulation of osteoblast activity, osteoclast activity, and calcium homeostasis. They regulate bone formation through wingless (Wnt)/ $\beta$-catenin signalling, a crucial pathway that directs the commitment of mesenchymal stem cells into osteoblastic lineage. Osteocytes secrete sclerostin (SOST) and Dickkopf-related protein 1 (DKK-1), which negatively regulate the activation of $\mathrm{Wnt} / \beta$-catenin by preventing the binding of Wnt ligands to the frizzled receptor, lipoprotein receptor-related protein (LRP) 5 and LRP6 [7]. The differentiation of osteoclast precursors into mature osteoclasts is mediated by osteoprotegerin (OPG) and the receptor activator of nuclear factor-kappa B ligand (RANKL) produced by osteocytes. The increased expression of RANKL facilitates osteoclastogenesis [8]. On the other hand, OPG inhibits osteoclastogenesis by binding to RANKL, thus preventing the receptor activator of nuclear factor-kappa B (RANK)-RANKL interaction. Fibroblast growth factor-23 (FGF-23) is also the products of osteocytes, whereas osteocytes are the critical effectors for parathyroid hormone (PTH) action. They are both implicated in the regulation of phosphate homeostasis and vitamin D metabolism, which reiterates their role in the maintenance of calcium homeostasis [9-11].

In view of the role of osteocytes in the synthesis of molecules essential for bone development, targeting the osteocyte-driven skeletal remodelling could be the next step in developing anti-osteoporotic agents. Several studies suggested that vitamin E could influence bone metabolism [12]. Vitamin E can be categorized into two major groups: tocotrienol and tocopherol. Each of these groups consist of four different isomers that are based on the location of methyl groups on the chromanol nucleus, namely alpha- $(\alpha-)$, beta- $(\beta-)$, gamma- $(\gamma-)$, and delta- $(\delta-)$ tocotrienol. Palm fruit and annatto seed are some of the abundant sources of tocotrienol. Palm-based tocotrienol contains approximately $75 \%$ tocotrienol and $25 \%$ tocopherol, whereas annatto-derived tocotrienol solely consists of tocotrienol (99.9\%) with the absence of tocopherol [13]. The ability of tocotrienol mixture to mitigate MetS-associated medical conditions [14] and bone deterioration $[15,16]$ has been well-established. Tocotrienol was found to alleviate MetS features through its potent anti-inflammatory [17], anti-oxidative [18,19] and cholesterol-reduction properties [20]. Besides, tocotrienol potentially mediates bone metabolism through regulating the release of inflammatory mediators, reactive oxygen species (ROS), growth factors, and hormones [12]. Interestingly, we found that the oral administration of annatto and palm tocotrienol conferred beneficial effects in reversing MetS features and preventing bone loss that is caused by MetS [21-23].

The effects of vitamin E on osteocytes have been reported by several researchers. A study by Jia et al. (2016) demonstrated the inhibitory effects of vitamin E (content not mentioned) on osteocyte apoptosis and oxidative damage using a rabbit model of osteonecrosis induced by steroid [24]. Another study by Hagan et al. (2019) indicated that the healthy mice fed with vitamin E-deficient diet had a higher percentage of wounded osteocytes but lower periosteal mineralizing surface, mineral apposition rate and bone formation rate when compared to the mice that were fed with regular diet [25]. In the same study, found that necrosis of MLO-Y4 osteocytes caused by hydrogen peroxide was prevented by vitamin E ( $\alpha$-tocopherol and Trolox) pre-treatment [25]. Another recent in vitro study indicated the 
anti-oxidative effects of palm-derived $\delta$-tocotrienol, protecting the MC3T3-E1 osteoblasts and MLO-Y4 osteocytes against oxidative damage that is induced by tert-butyl hydroperoxide [26]. These studies mainly focused on the effects of vitamin E on osteocyte viability through its capability of alleviating oxidative damage.

This present study aimed to assess the role of osteocytes in regulating bone remodelling in an animal model of bone loss that is induced by MetS. A panel of osteocyte-related peptides, including OPG, RANKL, SOST, DKK-1, FGF-23, and PTH, was evaluated in this study.

\section{Materials and Methods}

\subsection{Treatments}

Annatto tocotrienol that was derived from Bixa orellana containing $16 \% \gamma$-tocotrienol and $84 \%$ $\delta$-tocotrienol was a gift from American River Nutrition Inc. (Hadley, MA, USA) (Lot Number: 5D13-AMK2-70). Palm tocotrienol extracted from Elaeis guineensis containing $24.7 \% \alpha$-tocotrienol, $4.5 \% \beta$-tocotrienol, $36.9 \% \gamma$-tocotrienol, $12.0 \% \delta$-tocotrienol, and $21.9 \% \alpha$-tocopherol was a gift from Excelvite Sdn. Bhd. (Chemor, Malaysia) (Lot Number: A1/50/0159_1_120315). Annatto and palm tocotrienol were diluted with tocopherol-stripped corn oil (MP Biomedicals, Solon, $\mathrm{OH}$ ) prior to administration.

\subsection{Animal Experimentation}

The study protocol was reviewed and approved by Universiti Kebangsaan Malaysia Animal Ethics Committee (UKMAEC) (Approval Number: PP/FAR/2015/IMA/20-MAY/679-JUNE-2015-MAY-2017). Twelve-week-old male Wistar rats $(n=42)$ were purchased from Laboratory Animal Resource Unit (LARU), Universiti Kebangsaan Malaysia (Kuala Lumpur, Malaysia). The animals were singly housed in the Animal Facility of the Department of Anatomy, Faculty of Medicine, Universiti Kebangsaan Malaysia (Cheras, Malaysia) with the ambient temperature of $25 \pm 2{ }^{\circ} \mathrm{C}$ and alternated $12 \mathrm{~h}$ light-dark cycle. Food and water were provided ad libitum. Following acclimatization for one week, the animals were randomly assigned into seven experimental groups ( $n=6 /$ group). The baseline group was sacrificed after acclimatization. The normal group was fed with standard rat chow and tap water. The remaining five groups were given a high-carbohydrate high-fat (HCHF) diet with $25 \%$ fructose-supplemented drinking water to induce MetS [26]. The HCHF diet was prepared using $395 \mathrm{~g}$ sweetened condensed milk, $200 \mathrm{~g}$ ghee, $175 \mathrm{~g}$ fructose, $155 \mathrm{~g}$ powdered rat food, $25 \mathrm{~g}$ Hubble Mendel Wakeman salt mixture, and $50 \mathrm{~mL}$ water. The treatments were commenced at week 8 and given on a daily basis for 12 weeks. The normal animals were orally administrated with normal saline. The HCHF animals were orally treated with tocopherol-stripped corn oil (vehicle), $60 \mathrm{mg} / \mathrm{kg}$ annatto tocotrienol, $100 \mathrm{mg} / \mathrm{kg}$ annatto tocotrienol, $60 \mathrm{mg} / \mathrm{kg}$ palm tocotrienol, and $100 \mathrm{mg} / \mathrm{kg}$ palm tocotrienol. At week 20, the animals were sacrificed and right tibias were harvested for the measurement of bone-related peptides.

\subsection{Protein Extraction and Quantification}

Right tibias that were excised from the animals were cleaned of soft tissues and weighed. A transverse cut at the metaphysical region of the proximal right tibia $(15 \mathrm{~mm}$ from the proximal end of the tibia) (250-270 mg) was made (Figure 1). This region was selected, as our previous study detected a deterioration of trabecular bone microstructure in this animal model of bone loss induced by MetS [4]. Briefly, the excised bone section (both cortical and cancellous bone without fibula) was immersed with extraction buffer (containing $50 \mathrm{mM}$ Tris (pH 7.4), $150 \mathrm{mM}$ sodium chloride $(\mathrm{NaCl}), 1 \%$ Triton $\mathrm{X}-100,1 \%$ sodium deoxycholate $\left(\mathrm{C}_{24} \mathrm{H}_{39} \mathrm{O}_{4} \mathrm{Na}\right), 1 \mathrm{mM}$ ethylenediaminetetraacetic acid (EDTA), $0.1 \%$ sodium dodecyl sulphate (SDS), $10 \mathrm{nM}$ sodium fluoride $(\mathrm{NaF}), 1 \mathrm{mM}$ sodium orthovanadate $\left(\mathrm{Na}_{3} \mathrm{VO}_{4}\right)$, and $1 \mathrm{mM}$ phenylmethylsulfonyl fluoride (PMSF)) (Elabscience Biotechnology Inc., China) in bead ruptor tubes pre-filled with metal bead. The samples were homogenised using a high-speed homogenizer (OMNI Bead Ruptor 24, Kennesaw, GA) at the speed of $6.95 \mathrm{~m} / \mathrm{s}$ and cycle time of $8 \times 45$ 
$\mathrm{s}$ with $45 \mathrm{~s}$ dwells, followed by centrifugation at $8000 \mathrm{~g}$ for 10 minutes. Supernatant was collected and protein quantification of all bone samples was performed using Bradford method (Quick Start ${ }^{\mathrm{TM}}$ Bradford Protein Assay, Bio-Rad Laboratories Inc., CA, USA).

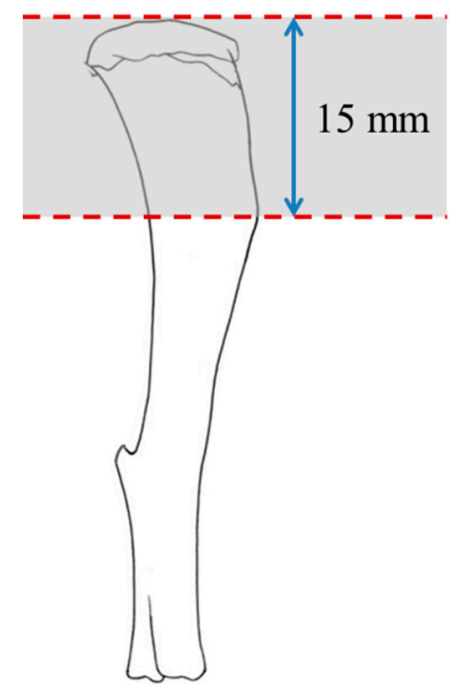

Figure 1. The metaphyseal region of tibia chosen for analysis.

\subsection{Assessment of Bone-Related Peptides}

Levels of OPG, SOST, DKK-1, FGF-23, and PTH in the metaphyseal region of the proximal tibia were quantified using Milliplex ${ }^{\circledR}$ Map Rat Bone Magnetic Bead Panel (Catalogue Number: RBN1MAG-31K, EMD Millipore Corporation, Billerica, USA) and measured using Luminex 100 (Multiplexed Biomarker Immunoassays for Luminex ${ }^{\circledR}$ Instrumentation/xMAP ${ }^{\circledR}$ Technology-Luminex Corporation, Austin, USA). The level of soluble receptor activator of nuclear factor-kappa B ligand (sRANKL) was determined using enzyme-linked immunosorbent assay kit, according to the manufacturer's instructions (Catalogue Number: ER1604, FineTest, Wuhan, China). The levels of bone-related peptides were normalised with the protein concentration of each sample.

\subsection{Statistical Analysis}

Statistical Package for Social Sciences (SPSS) version 20 (IBM, Armonk, USA) was used to perform statistical analysis. All the data were normally distributed. Statistical differences between groups were assessed by one-way analysis of variance (ANOVA) with Tukey's post-hoc pairwise comparison test. All of the results were presented as mean \pm standard error of the mean (SEM). $P$ values of $<0.05$ were considered to be statistically significant.

\section{Results}

The weight of right tibia did not show any significant difference between all of the experimental groups $(p=0.059)$ (Figure 2).

The assessment of bone-related peptides indicated that HCHF diet significantly raised the protein levels of sRANKL $(p<0.001)$, SOST $(p=0.001)$, DKK-1 $(p<0.001)$, FGF-23 $(p<0.001)$ and PTH $(p=0.001)$ as compared to the normal rats that were fed with standard diet. Supplementation of annatto and palm tocotrienol at the dose of 60 and $100 \mathrm{mg} / \mathrm{kg}$ reduced the levels sRANKL (60AnT3: $p<0.001$; 100AnT3: $p=0.002 ; 60$ pT3: $p<0.001$; 100pT3: $p<0.001$ ) and FGF-23 (60AnT3: $p<0.001$; 100AnT3: $p=0.001 ; 60$ T3: $p=0.014 ; 100$ TT3: $p=0.001$ ) relative to the vehicle-treated HCHF animals. Only $100 \mathrm{mg} / \mathrm{kg}$ annatto and palm tocotrienol prevented the increase of SOST (100AnT3: $p=0.003$; 100pT3: $p=0.003)$ and DKK-1 (100AnT3: $p=0.001 ; 100$ pT3: $p=0.023)$ levels in the HCHF animals as compared to the negative controls (Figure 3 ). 


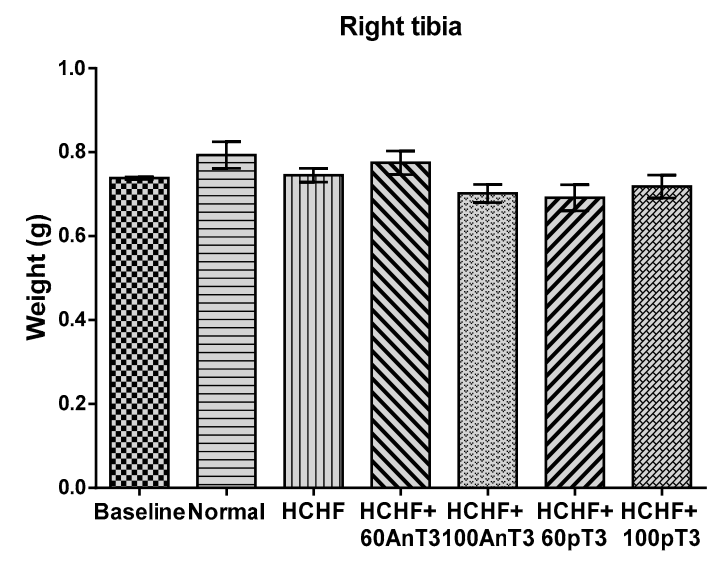

Figure 2. The weight of right tibia in the baseline, normal, high-carbohydrate high-fat (HCHF) animals with and without treatment of annatto and palm tocotrienol (60 and $100 \mathrm{mg} / \mathrm{kg}$ ). Data are presented as mean \pm SEM.
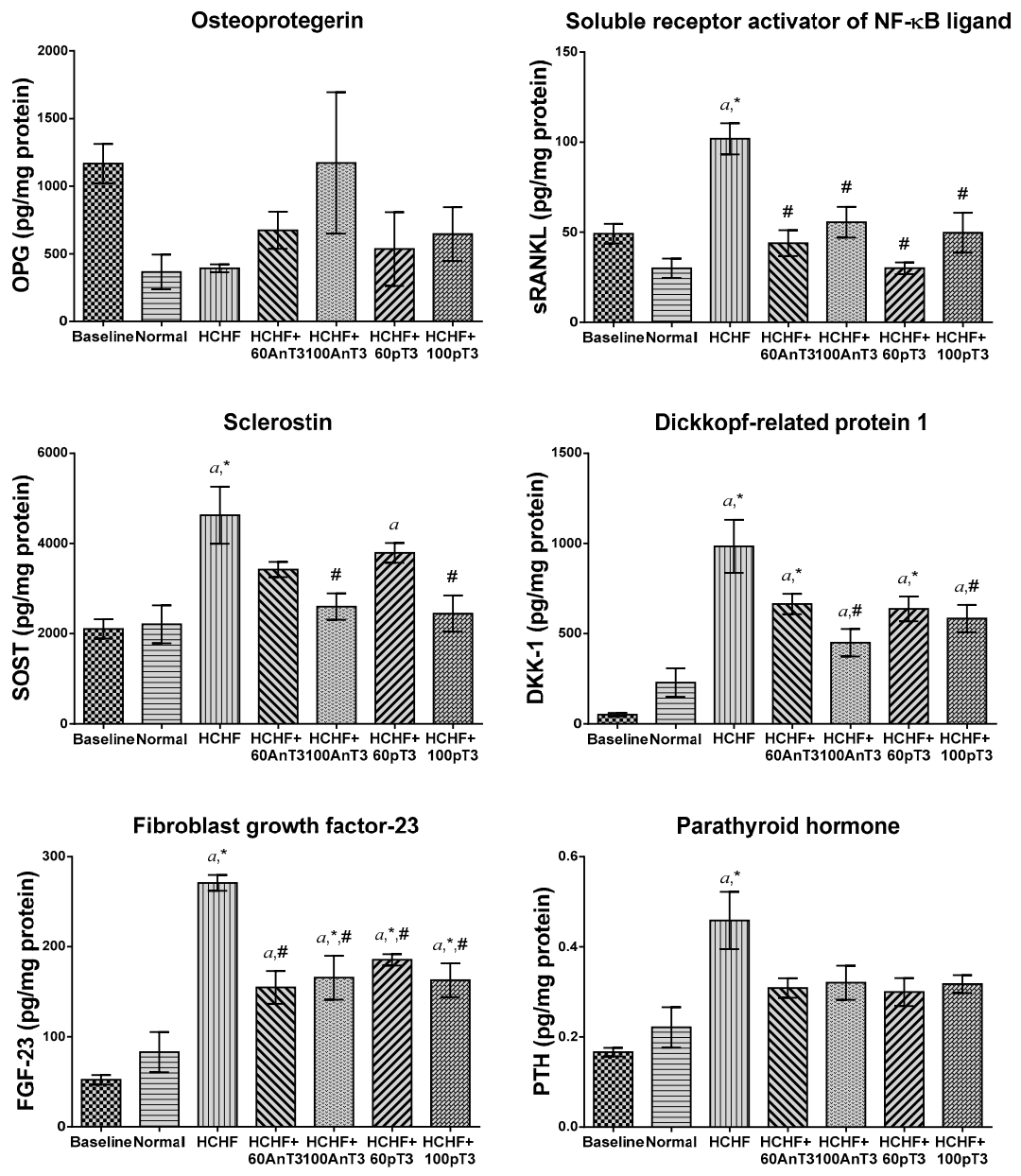

Figure 3. Level of osteoprotegerin (OPG), soluble receptor activator of nuclear factor-kappa B ligand (sRANKL), sclerostin (SOST), Dickkopf-related protein 1 (DKK-1), fibroblast growth factor-23 (FGF-23), and parathyroid hormone (PTH) in the baseline, normal, HCHF animals with and without treatment of annatto and palm tocotrienol (60 and $100 \mathrm{mg} / \mathrm{kg}$ ). Data are presented as mean \pm SEM. Letter ' $a$ ' indicates a significant difference $(p<0.05)$ compared to the baseline group, symbol '*' indicates a significant difference $(p<0.05)$ compared to the normal group and '\#' indicates a significant difference $(p<0.05)$ compared to the HCHF group. 


\section{Discussion}

In this study, we investigated the role of osteocyte in governing the process of bone metabolism using an osteoporotic rat model induced by MetS. The effects of annatto and palm tocotrienol supplementation on the osteocyte-derived secretory proteins (OPG, sRANKL, SOST, DKK-1, FGF-23, and $\mathrm{PTH}$ ) have been evaluated.

The RANK/RANKL/OPG system plays a central role in osteoblast-dependent osteoclastogenesis. Osteoblasts produce RANKL in response to local bone resorption-stimulating factors, such as inflammatory cytokines, hormones, and growth factors. RANKL binds to RANK on the osteoclast precursors to activate downstream signalling molecules (nuclear factor-kappa B (NF-kB), Fos proto-oncogene (c-Fos), and nuclear factor of activated T-cells cytoplasmic 1 (NFATc1)) for the completion of osteoclast differentiation process [27]. A previous study demonstrated the crucial role of osteocytes in the production of RANKL [28]. The authors reported that purified osteocytes expressed higher amount of RANKL than osteoblasts and bone marrow stromal cells in vitro, which suggested that osteocytes are the major source of RANKL; thus, have a greater capacity to regulate osteoclastogenesis [28]. The level of RANKL in osteocytes is tightly controlled by mechanical and hormonal stimuli. In vivo study indicated that mice lacking RANKL in osteocytes were protected from bone loss due to unloading [29]. In addition, PTH acts as a potent endocrine regulator for the expression of RANKL. A transgenic mice expressing constitutively active PTH receptor in osteocytes increased RANKL expression and bone remodelling rate [30]. On the contrary, conditional deletion of the PTH receptor from osteocytes resulted in decreased bone resorption and increased bone mass [31].

A decoy receptor for RANKL, which is known as OPG, is also produced by osteoblasts and osteocytes to prevent the RANKL-RANK interaction, thereby inhibiting osteoclastogenesis [6]. Theoretically, the upregulation of RANKL expression by inflammatory mediators, hormones, and growth factors is accompanied by a lower expression of OPG in osteoblasts and osteocytes, which results in osteoclastogenesis [32]. OPG is also regulated by the canonical Wnt $/ \beta$-catenin pathway. Without Wnt signal, $\beta$-catenin is readily degraded by a $\beta$-catenin destruction complex consisting of axin, adenomatous polyposis coli (APC), glycogen synthase kinase 3 (GSK3), and casein kinase 1 (CK1). The presence of Wnt signal binds to the receptor complex of frizzled, LRP5, and LRP6 causing the disruption of functional $\beta$-catenin destruction complex, which eventually leads to cytosolic accumulation and nuclear translocation of $\beta$-catenin. Subsequently, $\beta$-catenin binds to T-cell factor/lymphoid enhancing factor (Tcf/Lef) to initiate the transcription of OPG [33]. A previous in vivo study supported that osteocyte-specific $\beta$-catenin-deficient mice were osteoporotic due to the downregulation of OPG expression and increased osteoclast number and activity. However, the osteoblast function and osteocyte density of the mice were normal [34]. Apart from that, it has been proposed that PTH influences the expression of OPG. A study by Fu et al. (2002) indicated that PTH potently suppressed OPG expression in murine osteoblastic cells [35].

The canonical Wnt/ $\beta$-catenin pathway is governed through two important extracellular inhibitors, SOST and DKK-1. They are osteocyte-derived Wnt antagonists that antagonize the activation of $\mathrm{Wnt} / \beta$-catenin signalling by competitively binding to the LRP5 and LRP6 co-receptors [36]. Apart from being a negative modulator of $\mathrm{Wnt} / \beta$-catenin pathway, SOST is also a bone morphogenetic protein (BMP) antagonist that prevents the binding of BMPs to their receptors, suppresses BMP signalling and reduces the mineralization of osteoblastic cells [37]. Many preclinical studies provided evidence that the overexpression of SOST or DKK-1 in mice resulted in reduced bone mass [37-41], whereas mice with the deficiency of SOST and DKK-1 gene displayed increased bone formation and higher bone mass [42-44]. Mechanical loading and PTH were found to negatively regulate the levels of SOST and DKK-1 expression [38,45-47]. Hence, the activation of Wnt signalling not only stimulates osteoblast activity, but it also attenuates osteoclast differentiation and function by stimulating the production of OPG.

Fibroblast growth factor-23 is a protein that is primarily secreted by osteocytes and osteoblasts [48]. It is a known regulator responsible for phosphate homeostasis and vitamin D metabolism, thus having 
a pivotal role in the pathophysiology of bone disorders. FGF-23 suppresses the expression of sodium-phosphate co-transporter gene (NPT2) in the proximal renal tubule, thus decreasing reabsorption and increasing the urinary excretion of phosphate [10]. In addition, FGF-23 inhibits $1 \alpha$-hydroxylase, thereby diminishing the conversion of 25 -hydroxyvitamin $\mathrm{D}[25(\mathrm{OH}) \mathrm{D}]$ to active 1,25-dihydroxyvitamin $\mathrm{D}\left[1,25(\mathrm{OH})_{2} \mathrm{D}\right]$ and impairing calcium absorption [11]. Therefore, a high level of FGF-23 is associated with the inhibition of bone mineralization. Under physiological condition, the recognition of FGF-23 by FGF cell-surface receptors (FGFRs) requires the presence of Klotho, which is a transmembrane protein that acts as cofactor facilitating the binding and activation of FGFRs by FGF-23 [49]. Osteoblastic MC3T3-E1 cells exogenously supplemented with FGF-23 and Klotho showed reduced mineralization and osteoblast differentiation markers, including alkaline phosphatase (ALP), osteocalcin (OCN), collagen type 1 alpha 1 (COL1 $\alpha 1)$, bone sialoprotein (BSP), and osteopontin (OPN) [50].

Parathyroid hormone mainly acts on three major organs (kidney, intestine, and bone) to regulate the extracellular calcium and phosphate homeostasis [9], thus suggesting its role in orchestrating bone metabolism. In bone, apart from osteoblasts and chondrocytes, increasing evidence demonstrates that osteocytes are a crucial cellular target of PTH. The interaction between PTH and its membrane receptor, which is known as PTH/PTH-related protein type 1 receptor (PTHR1), results in both anabolic and catabolic skeletal responses. As aforementioned, PTH exhibited osteogenic action through the downregulation of SOST and DKK-1 (potent inhibitors of Wnt signalling), leading to increased bone formation [51]. In contrast, PTH induces osteoclastogenesis via differential regulation of OPG and RANKL, whereby OPG expression is downregulated, but RANKL expression is upregulated [52]. However, the expression of OPG might be unaffected, as it is likely counteracted by increased OPG expression resulting from Wnt activation [51]. The effects of PTH on bone, either anabolic or catabolic, depend on the duration and periodicity of PTH exposure. The transient exposure to PTH leads to enhanced bone formation, whereas sustained exposure to PTH leads to increased bone resorption $[53,54]$.

In this current study, we observed the increase in sRANKL, SOST, DKK-1, and FGF-23 levels in the bones of the animals after being challenged with HCHF diet, whereby it might be due to the increase in the PTH level. The findings were supported by a previous study indicating that high-fat diet-induced hyperlipidaemia caused hyperparathyroidism and impaired bone regeneration and mechanical strength in mice [55]. The results from a previous human study also showed that there was a positive association between the risk of MetS and PTH level [56]. However, evidence on the effects of diet-induced MetS on the levels of other bone peptides (OPG, sRANKL, SOST, DKK-1 and FGF-23) is limited. The increase in cytokines [including interleukin-6 (IL-6) and interleukin-1 alpha (IL-1 $\alpha$ )] was also detected in the animals that were treated with HCHF diet [21,23], possibly contributing to the increase of sRANKL in bone. There was no significant change in the level of OPG among all of the experimental groups in our present study. The possible explanation could be the direct action of PTH and inflammatory mediators in downregulating OPG expression was counteracted by the indirect action of PTH in downregulating SOST and DKK-1 expression, leading to the activation of Wnt/ $\beta$-catenin and upregulation of OPG expression. Mechanical loading and unloading might not be the factors that account for the alteration in the level of these bone-related peptides (sRANKL, SOST and DKK-1) in this study because no change in the body weight of animals among all of the experimental groups was observed [21,23]. Overall, our findings demonstrated that MetS increased the levels of sRANKL, SOST, DKK-1, FGF-23, and PTH at the osteocyte level, translating into the dysregulation of the bone formation and resorption in the animals.

The osteoprotective effects of tocotrienol were mediated through the normalization of these osteocyte-derived products. Annatto and palm tocotrienol at the dose of 60 and $100 \mathrm{mg} / \mathrm{kg}$ reduced the elevated sRANKL and FGF-23 in animals caused by long-term feeding of HCHF diet. The findings were in line with previous in vitro study that $50 \mu \mathrm{M}$ of $\alpha$-tocotrienol suppressed RANKL expression in osteoblasts and RANKL-induced expression of c-Fos and NFATc1 by inhibiting 
extracellular-signal-regulated kinase (ERK) and NF-kB activation [57]. Another study also revealed that Trolox (a water-soluble $\alpha$-tocopherol) suppressed the IL-10-induced RANKL expression in the co-culture of osteoblasts and bone marrow cells [58]. The effects of tocotrienol treatment on FGF-23 level was previously evaluated by Ibrahim et al. (2015) using ovariectomized female rats with fracture. In that study, their results indicated that injection of tocotrienol particles for four weeks did not cause any change in the FGF-23 gene expression [59]. The distinct outcome observed between the current study and their study might be due to the variations of study design in terms of the treatment regimen, route of administration, treatment period, and type of animal model. The level of OPG was unaffected after the treatment of annatto and palm tocotrienol in the present study. Per the current findings, previous in vitro [57] and in vivo [60] studies have reported that tocotrienol did not alter OPG expression by osteoblasts. Higher doses of annatto and palm tocotrienol conferred better outcomes, whereby the increase in SOST and DKK-1 levels in the animals with MetS was prevented. A comparable study on the effects of tocotrienol on these parameters is limited. For PTH, treatment with tocotrienol did not cause any change in the HCHF diet-fed animals. We hypothesize that a longer period of treatment might be needed to reverse the elevated PTH level in the HCHF animals. In congruent with the current findings, a study by Norazlina et al. (2004) found that rats fed with vitamin E-deficient diet had a higher level of PTH, but the supplementation of vitamin E ( $\alpha$-tocotrienol and $\alpha$-tocopherol) for three months did not cause any change in the PTH level [61].

A schematic diagram that summarizes the postulated actions of osteocyte-derived molecules in MetS-induced bone loss and the effects of tocotrienol in osteocyte-driven bone remodelling is shown in Figure 4. Several limitations need to be addressed in this study. Firstly, the measurement of bone peptides was only performed at the end of the study, so we cannot monitor the sequential changes in their level throughout the study period. Secondly, circulating vitamin D level was not determined. Previous studies suggested that adipose tissue could sequester vitamin $\mathrm{D}$ and reduce its circulating level. Thirdly, we did not flush out the bone marrow prior to analysis, thus the role of mesenchymal stem cells on osteoblastogenesis and osteoclastogenesis should not be ruled out. Nonetheless, this is the first study investigating the role of osteocyte-related peptides in regulating bone metabolism using a MetS-induced osteoporotic rat model that was treated with tocotrienol.

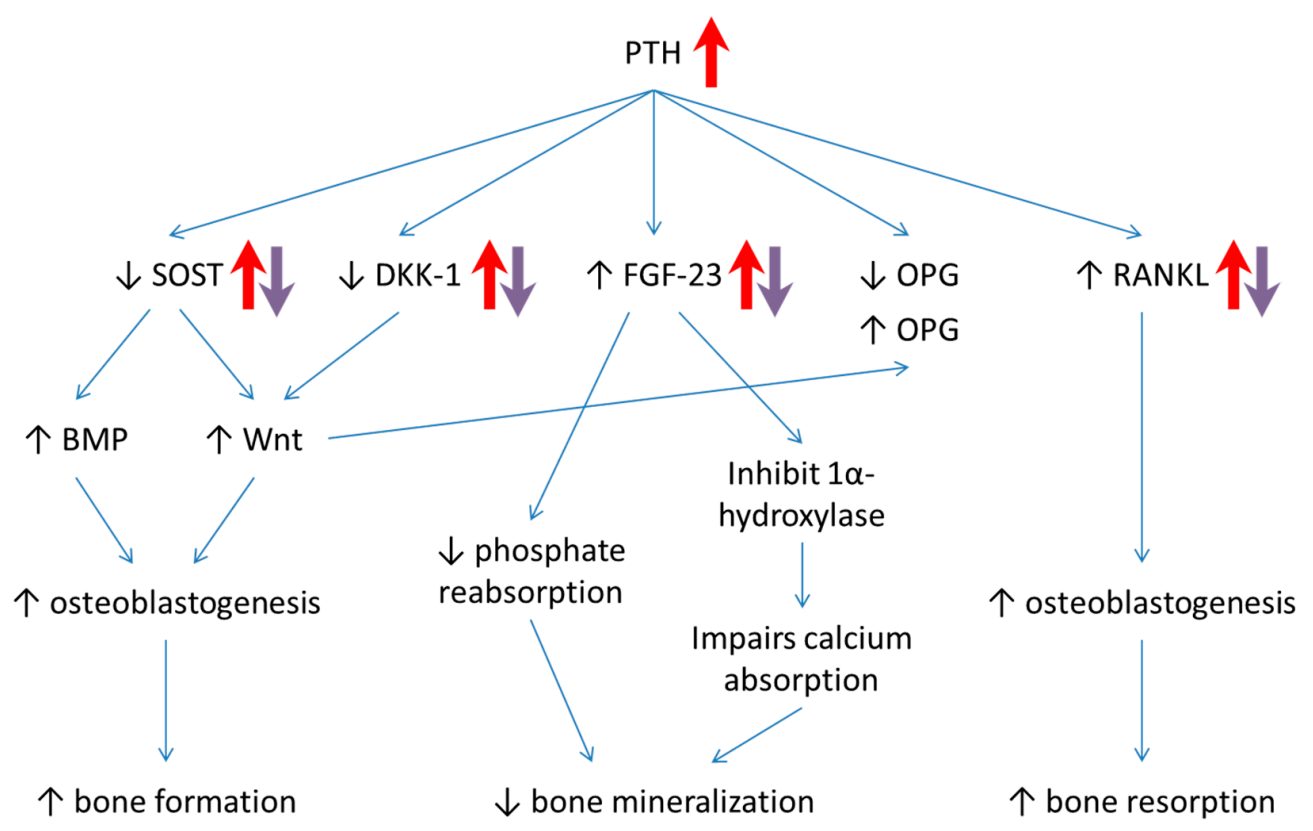

Figure 4. The postulated role of osteocyte-derived bone peptides (OPG, sRANKL, SOST, DKK-1, FGF-23, and PTH) in regulating bone remodelling processes. The red arrows indicate the protein levels in rats after challenged with HCHF diet for 20 weeks. The purple arrows indicate the protein levels in rats in response to the treatment with tocotrienol. 


\section{Conclusions}

MetS mainly causes bone loss by increasing the levels of sRANKL, SOST, DKK-1, and FGF-23, leading to an imbalance between bone formation and resorption. Treatment with tocotrienol for 12 weeks can normalize the changes in these bone-related peptides that were caused by MetS, thus reiterating the anti-osteoporotic potential of tocotrienol. The findings from present studies support the idea that osteocytes are important coordinators for bone metabolism. Future pharmacologic approach for the prevention and treatment of osteoporosis may focus on targeting osteocytes to increase bone mass and bone strength.

Author Contributions: Conceptualization, K.-Y.C. and S.I.-N.; methodology, S.K.W.; software, S.K.W.; validation, K.-Y.C. and S.I.-N.; formal analysis, S.K.W.; investigation, S.K.W.; resources, K.-Y.C. and S.I.-N.; data curation, S.K.W.; writing-original draft preparation, S.K.W.; writing—review and editing, K.-Y.C. and S.I.-N.; visualization, S.K.W.; supervision, K.-Y.C. and S.I.-N.; project administration, K.-Y.C. and S.I.-N.; funding acquisition, K.-Y.C. and S.I.-N.

Funding: This research was funded by Universiti Kebangsaan Malaysia, grant number MI-2019-006 and FF-2018-410.

Acknowledgments: We thank American River Nutrition and Excelvite Sdn Bhd for sponsoring the annatto and palm tocotrienol, respectively.

Conflicts of Interest: The authors declare no conflict of interest.

\section{References}

1. Wong, S.K.; Chin, K.-Y.; Suhaimi, F.H.; Ahmad, F.; Ima-Nirwana, S. The Relationship between Metabolic Syndrome and Osteoporosis: A Review. Nutrients 2016, 8, 347. [CrossRef] [PubMed]

2. Wong, S.K.; Chin, K.Y.; Suhaimi, F.H.; Ahmad, F.; Ima-Nirwana, S. The Effects of a Modified High-carbohydrate High-fat Diet on Metabolic Syndrome Parameters in Male Rats. Exp. Clin. Endocrinol. Diabetes 2018, 126, 205-212. [CrossRef] [PubMed]

3. Wong, S.K.; Chin, K.-Y.; Suhaimi, F.H.; Ahmad, F.; Ima-Nirwana, S. Effects of metabolic syndrome on bone mineral density, histomorphometry and remodelling markers in male rats. PLoS ONE 2018, 13, e0192416. [CrossRef] [PubMed]

4. Wong, S.K.; Chin, K.-Y.; Suhaimi, F.H.; Ahmad, F.; Jamil, N.A.; Ima-Nirwana, S. Osteoporosis is associated with metabolic syndrome induced by high-carbohydrate high-fat diet in a rat model. Biomed. Pharmacother. 2018, 98, 191-200. [CrossRef] [PubMed]

5. Delgado-Calle, J.; Bellido, T. Osteocytes and Skeletal Pathophysiology. Curr. Mol. Boil. Rep. 2015, 1, 157-167. [CrossRef] [PubMed]

6. Bellido, T. Osteocyte-driven bone remodeling. Calcif. Tissue Int. 2014, 94, 25-34. [CrossRef]

7. Baron, R.; Kneissel, M. WNT signaling in bone homeostasis and disease: From human mutations to treatments. Nat. Med. 2013, 19, 179-192. [CrossRef]

8. Khosla, S. Minireview: The OPG/RANKL/RANK System. Endocrinology 2001, 142, 5050-5055. [CrossRef]

9. Gensure, R.C.; Gardella, T.J.; Jüppner, H. Parathyroid hormone and parathyroid hormone-related peptide, and their receptors. Biochem. Biophys. Res. Commun. 2005, 328, 666-678. [CrossRef]

10. Jüppner, H. Phosphate and FGF-23. Kidney Int. 2011, 79, S24-S27. [CrossRef]

11. Perwad, F.; Zhang, M.Y.; Tenenhouse, H.S.; Portale, A.A. Fibroblast growth factor 23 impairs phosphorus and vitamin D metabolism in vivo and suppresses 25-hydroxyvitamin D-1alpha-hydroxylase expression in vitro. Am. J. Physiol. Renal. Physiol. 2007, 293, F1577-F1583. [CrossRef] [PubMed]

12. Wong, S.K.; Mohamad, N.V.; Ibrahim, N.; Chin, K.Y.; Shuid, A.N.; Ima-Nirwana, S. The Molecular Mechanism of Vitamin E as a Bone-Protecting Agent: A Review on Current Evidence. Int. J. Mol. Sci. 2019, 20, 1453. [CrossRef] [PubMed]

13. Aggarwal, B.B.; Sundaram, C.; Prasad, S.; Kannappan, R. Tocotrienols, the Vitamin E of the 21st Century: It's Potential Against Cancer and Other Chronic Diseases. Biochem. Pharmacol. 2010, 80, 1613-1631. [CrossRef] [PubMed] 
14. Wong, S.K.; Chin, K.-Y.; Suhaimi, F.H.; Ahmad, F.; Ima-Nirwana, S.; Vitamin, E. As a Potential Interventional Treatment for Metabolic Syndrome: Evidence from Animal and Human Studies. Front. Pharmacol. 2017, 8, 444. [CrossRef] [PubMed]

15. Chin, K.-Y.; Ima-Nirwana, S. The biological effects of tocotrienol on bone: A review on evidence from rodent models. Drug Des. Dev. Ther. 2015, 9, 2049-2061. [CrossRef] [PubMed]

16. Chin, K.-Y.; Ima-Nirwana, S. The Role of Tocotrienol in Preventing Male Osteoporosis-A Review of Current Evidence. Int. J. Mol. Sci. 2019, 20, 1355. [CrossRef]

17. Zhao, L.; Kang, I.; Fang, X.; Wang, W.; Lee, M.A.; Hollins, R.R.; Marshall, M.R.; Chung, S. Gamma-tocotrienol attenuates high-fat diet-induced obesity and insulin resistance by inhibiting adipose inflammation and M1 macrophage recruitment. Int. J. Obes. 2015, 39, 438-446. [CrossRef]

18. Kuhad, A.; Chopra, K. Attenuation of diabetic nephropathy by tocotrienol: Involvement of NFkB signaling pathway. Life Sci. 2009, 84, 296-301. [CrossRef]

19. Burdeos, G.C.; Nakagawa, K.; Kimura, F.; Miyazawa, T. Tocotrienol Attenuates Triglyceride Accumulation in HepG2 Cells and F344 Rats. Lipids 2012, 47, 471-481. [CrossRef]

20. Shibata, A.; Kawakami, Y.; Kimura, T.; Miyazawa, T.; Nakagawa, K. Alpha-Tocopherol Attenuates the Triglyceride- and Cholesterol-Lowering Effects of Rice Bran Tocotrienol in Rats Fed a Western Diet. J. Agric. Food Chem. 2016, 64, 5361-5366. [CrossRef]

21. Wong, S.K.; Chin, K.-Y.; Suhaimi, F.H.; Ahmad, F.; Ima-Nirwana, S. Exploring the potential of tocotrienol from Bixa orellana as a single agent targeting metabolic syndrome and bone loss. Bone 2018, 116, 8-21. [CrossRef] [PubMed]

22. Wong, S.K.; Chin, K.-Y.; Suhaimi, F.H.; Ahmad, F.; Ima-Nirwana, S. The Effects of Vitamin E from Elaeis guineensis (Oil Palm) in a Rat Model of Bone Loss Due to Metabolic Syndrome. Int. J. Environ. Res. Public Heal. 2018, 15, 1828. [CrossRef] [PubMed]

23. Wong, S.K.; Chin, K.-Y.; Suhaimi, F.H.; Ahmad, F.; Ima-Nirwana, S. The effects of palm tocotrienol on metabolic syndrome and bone loss in male rats induced by high-carbohydrate high-fat diet. J. Funct. Foods 2018, 44, 246-254. [CrossRef]

24. Jia, Y.-B.; Jiang, D.-M.; Ren, Y.-Z.; Liang, Z.-H.; Zhao, Z.-Q.; Wang, Y.-X. Inhibitory effects of vitamin E on osteocyte apoptosis and DNA oxidative damage in bone marrow hemopoietic cells at early stage of steroid-induced femoral head necrosis. Mol. Med. Rep. 2017, 15, 1585-1592. [CrossRef] [PubMed]

25. Hagan, M.L.; Bahraini, A.; Pierce, J.L.; Bass, S.M.; Yu, K.; Elsayed, R.; Elsalanty, M.; Johnson, M.H.; McNeil, A.; McNeil, P.L.; et al. Inhibition of Osteocyte Membrane Repair Activity via Dietary Vitamin E Deprivation Impairs Osteocyte Survival. Calcif. Tissue Int. 2019, 104, 224-234. [CrossRef] [PubMed]

26. Casati, L.; Pagani, F.; Limonta, P.; Vanetti, C.; Stancari, G.; Sibilia, V. Beneficial effects of delta-tocotrienol against oxidative stress in osteoblastic cells: Studies on the mechanisms of action. Eur. J. Nutr. 2019, 1-13.

27. Boyce, B.F.; Xing, L. Functions of RANKL/RANK/OPG in bone modeling and remodeling. Arch. Biochem. Biophys. 2008, 473, 139-146. [CrossRef] [PubMed]

28. Nakashima, T.; Hayashi, M.; Fukunaga, T.; Kurata, K.; Oh-Hora, M.; Feng, J.Q.; Bonewald, L.F.; Kodama, T.; Wutz, A.; Wagner, E.F.; et al. Evidence for osteocyte regulation of bone homeostasis through RANKL expression. Nat. Med. 2011, 17, 1231-1234. [CrossRef] [PubMed]

29. Xiong, J.; Onal, M.; Jilka, R.L.; Weinstein, R.S.; Manolagas, S.C.; O’Brien, C.A. Matrix-embedded cells control osteoclast formation. Nat. Med. 2011, 17, 1235-1241. [CrossRef]

30. O’Brien, C.A.; Plotkin, L.I.; Galli, C.; Goellner, J.J.; Gortázar, A.R.; Allen, M.R.; Robling, A.G.; Bouxsein, M.; Schipani, E.; Turner, C.H.; et al. Control of Bone Mass and Remodeling by PTH Receptor Signaling in Osteocytes. PLoS ONE 2008, 3, e2942. [CrossRef]

31. Tu, X.; Edwards, R.; Olivos, N.; Benson, J.; Galli, C.; Pellegrini, G.; Bivi, N.; Plotkin, L.; Bellido, T. Conditional deletion of the parathyroid hormone (PTH) receptor 1 from osteocytes results in decreased bone resorption and a progressive increase in cancellous bone mass. J. Bone Miner. Res. 2011, 26, S16.

32. Boyce, B.F.; Xing, L. The RANKL/RANK/OPG pathway. Curr. Osteoporos. Rep. 2007, 5, 98-104. [CrossRef] [PubMed]

33. Kobayashi, Y.; Uehara, S.; Koide, M.; Takahashi, N. The regulation of osteoclast differentiation by Wnt signals. BoneKEy Rep. 2015, 4, 713. [CrossRef] [PubMed] 
34. Kramer, I.; Halleux, C.; Keller, H.; Pegurri, M.; Gooi, J.H.; Weber, P.B.; Feng, J.Q.; Bonewald, L.F.; Kneissel, M. Osteocyte Wnt/beta-catenin signaling is required for normal bone homeostasis. Mol. Cell. Biol. 2010, 30, 3071-3085. [CrossRef] [PubMed]

35. Fu, Q.; Jilka, R.L.; Manolagas, S.C.; O’Brien, C.A. Parathyroid hormone stimulates receptor activator of NFkappa B ligand and inhibits osteoprotegerin expression via protein kinase A activation of cAMP-response element-binding protein. J. Biol. Chem. 2002, 277, 48868-48875. [CrossRef] [PubMed]

36. Bonewald, L.F. The amazing osteocyte. J. Bone Miner. Res. 2011, 26, 229-238. [CrossRef] [PubMed]

37. Winkler, D.G.; Sutherland, M.K.; Geoghegan, J.C.; Yu, C.; Hayes, T.; Skonier, J.E.; Shpektor, D.; Jonas, M.; Kovacevich, B.R.; Staehling-Hampton, K.; et al. Osteocyte control of bone formation via sclerostin, a novel BMP antagonist. EMBO J. 2003, 22, 6267-6276. [CrossRef] [PubMed]

38. Guo, J.; Liu, M.; Yang, D.; Bouxsein, M.L.; Saito, H.; Galvin, R.S.; Kuhstoss, S.A.; Thomas, C.C.; Schipani, E.; Baron, R.; et al. Suppression of Wnt signaling by Dkk1 attenuates PTH-mediated stromal cell response and new bone formation. Cell Metab. 2010, 11, 161-171. [CrossRef]

39. Yao, G.-Q.; Wu, J.-J.; Troiano, N.; Insogna, K. Targeted overexpression of Dkk1 in osteoblasts reduces bone mass but does not impair the anabolic response to intermittent PTH treatment in mice. J. Bone Mine.r Metab. 2011, 29, 141-148. [CrossRef]

40. Kramer, I.; Loots, G.G.; Studer, A.; Keller, H.; Kneissel, M. Parathyroid hormone (PTH)-induced bone gain is blunted in SOST overexpressing and deficient mice. J. Bone Miner. Res. 2010, 25, 178-189. [CrossRef]

41. Li, J.; Sarosi, I.; Cattley, R.C.; Pretorius, J.; Asuncion, F.; Grisanti, M.; Morony, S.; Adamu, S.; Geng, Z.; Qiu, W.; et al. Dkk1-mediated inhibition of Wnt signaling in bone results in osteopenia. Bone 2006, 39, 754-766. [CrossRef] [PubMed]

42. Li, X.; Ominsky, M.S.; Niu, Q.-T.; Sun, N.; Daugherty, B.; D’Agostin, D.; Kurahara, C.; Gao, Y.; Cao, J.; Gong, J.; et al. Targeted Deletion of the Sclerostin Gene in Mice Results in Increased Bone Formation and Bone Strength. J. Bone Miner. Res. 2008, 23, 860-869. [CrossRef] [PubMed]

43. Morvan, F.; Boulukos, K.; Clément-Lacroix, P.; Roman, S.R.; Suc-Royer, I.; Vayssière, B.; Ammann, P.; Martin, P.; Pinho, S.; Pognonec, P.; et al. Deletion of a Single Allele of the Dkk1 Gene Leads to an Increase in Bone Formation and Bone Mass. J. Bone Miner. Res. 2006, 21, 934-945. [CrossRef]

44. MacDonald, B.T.; Joiner, D.M.; Oyserman, S.M.; Sharma, P.; Goldstein, S.A.; He, X.; Hauschka, P.V. Bone mass is inversely proportional to Dkk1 levels in mice. Bone 2007, 41, 331-339. [CrossRef] [PubMed]

45. Robling, A.G.; Niziolek, P.J.; Baldridge, L.A.; Condon, K.W.; Allen, M.R.; Alam, I.; Mantila, S.M.; Gluhak-Heinrich, J.; Bellido, T.M.; Harris, S.E.; et al. Mechanical stimulation of bone in vivo reduces osteocyte expression of Sost/sclerostin. J. Biol. Chem. 2008, 283, 5866-5875. [CrossRef] [PubMed]

46. Drake, M.T.; Srinivasan, B.; Mödder, U.I.; Peterson, J.M.; McCready, L.K.; Riggs, B.L.; Dwyer, D.; Stolina, M.; Kostenuik, P.; Khosla, S. Effects of Parathyroid Hormone Treatment on Circulating Sclerostin Levels in Postmenopausal Women. J. Clin. Endocrinol. Metab. 2010, 95, 5056-5062. [CrossRef] [PubMed]

47. Holguin, N.; Brodt, M.D.; Silva, M.J. Activation of Wnt Signaling by Mechanical Loading Is Impaired in the Bone of Old Mice. J. Bone Miner. Res. 2016, 31, 2215-2226. [CrossRef]

48. Guo, Y.-C.; Yuan, Q. Fibroblast growth factor 23 and bone mineralisation. Int. J. Oral Sci. 2015, 7, 8-13. [CrossRef]

49. Chen, G.; Liu, Y.; Goetz, R.; Fu, L.; Jayaraman, S.; Hu, M.C.; Moe, O.W.; Liang, G.; Li, X.; Mohammadi, M. Alpha-Klotho is a non-enzymatic molecular scaffold for FGF23 hormone signalling. Nature 2018, 553, 461-466. [CrossRef]

50. Shalhoub, V.; Ward, S.C.; Sun, B.; Stevens, J.; Renshaw, L.; Hawkins, N.; Richards, W.G. Fibroblast Growth Factor 23 (FGF23) and Alpha-Klotho Stimulate Osteoblastic MC3T3.E1 Cell Proliferation and Inhibit Mineralization. Calcif. Tissue Int. 2011, 89, 140-150. [CrossRef]

51. Bellido, T.; Saini, V.; Pajevic, P.D. Effects of PTH on osteocyte function. Bone 2013, 54, 250-257. [CrossRef] [PubMed]

52. Wein, M.N. Parathyroid Hormone Signaling in Osteocytes. JBMR Plus 2017, 2, 22-30. [CrossRef] [PubMed]

53. Kim, S.W.; Pajevic, P.D.; Selig, M.; Barry, K.J.; Yang, J.Y.; Shin, C.S.; Baek, W.Y.; Kim, J.E.; Kronenberg, H.M. Intermittent parathyroid hormone administration converts quiescent lining cells to active osteoblasts. J. Bone Miner. Res. 2012, 27, 2075-2084. [CrossRef] [PubMed]

54. Silva, B.C.; Bilezikian, J.P. Parathyroid hormone: Anabolic and catabolic actions on the skeleton. Curr. Opin. Pharmacol. 2015, 22, 41-50. [CrossRef] [PubMed] 
55. Pirih, F.; Lu, J.; Ye, F.; Bezouglaia, O.; Atti, E.; Ascenzi, M.; Tetradis, S.; Demer, L.; Aghaloo, T.; Tintut, Y. Adverse Effects of Hyperlipidemia on Bone Regeneration and Strength. J. Bone Miner. Res. 2012, 27, 309-318. [CrossRef] [PubMed]

56. Reis, J.P.; Kritz-Silverstein, D.; Wingard, D.L.; Barrett-Connor, E.; Von Mühlen, D. Vitamin D, Parathyroid Hormone Levels, and the Prevalence of Metabolic Syndrome in Community-Dwelling Older Adults. Diabetes Care 2007, 30, 1549-1555. [CrossRef]

57. Ha, H.; Lee, J.H.; Kim, H.N.; Lee, Z.H. alpha-Tocotrienol inhibits osteoclastic bone resorption by suppressing RANKL expression and signaling and bone resorbing activity. Biochem. Biophys. Res. Commun. 2011, 406, 546-551. [CrossRef]

58. Lee, Z.; Lee, J.; Kim, H.; Yang, D.; Jung, K.; Ha, H. Trolox prevents osteoclastogenesis by suppressing RANKL expression and signaling. Bone 2009, 44, S140-S141. [CrossRef]

59. Ibrahim, N.; Mohamed, N.; Soelaiman, I.N.; Shuid, A.N. The Effects of Targeted Deliveries of Lovastatin and Tocotrienol on Ossification-Related Gene Expressions in Fracture Healing in an Osteoporosis Rat Model. Int. J. Environ. Res. Public Heal. 2015, 12, 12958-12976. [CrossRef]

60. Norazlina, M.; Maizatul-Neza, J.; Azarina, A.; Nazrun, A.S.; Norliza, M.; Ima-Nirwana, S. Effects of vitamin E on receptor activator of nuclear factor kappa B ligand (RANKL) and osteoprotegerin (OPG) in rats treated with nicotine. Med J. Malays. 2010, 65, 14-17.

61. Norazlina, M.; Chua, C.W.; Ima-Nirwana, S. Vitamin E deficiency reduced lumbar bone calcium content in female rats. Med J. Malays. 2004, 59, 623-630.

(C) 2019 by the authors. Licensee MDPI, Basel, Switzerland. This article is an open access article distributed under the terms and conditions of the Creative Commons Attribution (CC BY) license (http://creativecommons.org/licenses/by/4.0/). 